\title{
Article \\ The Prevalence of Cardiac Diseases in a Contemporary Large Cohort of Dutch Elderly Ankylosing Spondylitis Patients- The CARDAS Study
}

\author{
Milad Baniaamam ${ }^{1,2}, *$, Sjoerd C. Heslinga ${ }^{3}$, Laura Boekel ${ }^{1}$, Thelma C. Konings ${ }^{4}$, M. Louis Handoko ${ }^{4}$, \\ Otto Kamp ${ }^{4}$, Vokko P. van Halm ${ }^{4}$, Irene E. van der Horst-Bruinsma ${ }^{3}$ and Mike T. Nurmohamed ${ }^{1,2,3}$ \\ 1 Reade Rheumatology, Amsterdam Rheumatology and Immunology Center, \\ 1056 AB Amsterdam, The Netherlands; 1.boekel@reade.nl (L.B.); m.nurmohamed@reade.nl (M.T.N.) \\ 2 Amsterdam Cardiovascular Sciences, Vrije Universiteit, 1081 HV Amsterdam, The Netherlands \\ 3 Department of Rheumatology, Amsterdam UMC, Vrije Universiteit Amsterdam, \\ 1081 HV Amsterdam, The Netherlands; scheslinga@gmail.com (S.C.H.); \\ i.e.vanderhorst@amsterdamumc.nl (I.E.v.d.H.-B.) \\ 4 Department of Cardiology, Amsterdam UMC, Vrije Universiteit Amsterdam, \\ 1081 HV Amsterdam, The Netherlands; t.konings@amsterdamumc.nl (T.C.K.); \\ ml.handoko@amsterdamumc.nl (M.L.H.); o.kamp@amsterdamumc.nl (O.K.); \\ v.p.vanhalm@amsterdamumc.nl (V.P.v.H.) \\ check for
} updates

Citation: Baniaamam, M.; Heslinga, S.C.; Boekel, L.; Konings, T.C.; Handoko, M.L.; Kamp, O.; van Halm, V.P.; van der Horst-Bruinsma, I.E.; Nurmohamed, M.T. The

Prevalence of Cardiac Diseases in a Contemporary Large Cohort of Dutch Elderly Ankylosing Spondylitis Patients-The CARDAS Study. J. Clin. Med. 2021, 10, 5069. https://doi.org/10.3390/jcm10215069

Academic Editor: Salvatore D'Angelo

Received: 13 October 2021

Accepted: 28 October 2021

Published: 29 October 202

Publisher's Note: MDPI stays neutral with regard to jurisdictional claims in published maps and institutional affiliations.

Copyright: (C) 2021 by the authors Licensee MDPI, Basel, Switzerland. This article is an open access article distributed under the terms and conditions of the Creative Commons Attribution (CC BY) license (https:// creativecommons.org/licenses/by/ $4.0 /)$.
Abstract: Objectives: The aim of the present study was to determine the prevalence of specific cardiac manifestations, i.e., conduction disorders, valvular disease and diastolic left ventricular (LV) dysfunction, in a large cross-sectional controlled cohort of elderly ankylosing spondylitis (AS) patients. Methods: This cross-sectional study assessed the prevalence of valvular disease, conduction disorders and LV dysfunction in 193 randomly selected AS patients compared with 74 osteoarthritis (OA) controls aged 50-75 years. Patients underwent conventional and tissue Doppler echocardiography in combination with clinical and laboratory assessments. Multivariate regression analyses were performed to compare the odds of mitral valve regurgitation (MVR) and aortic valve regurgitation (AVR) between AS patients and OA controls. Results: The prevalence of diastolic dysfunction was trivial and comparable in AS patients compared to controls (respectively, 4\% and 3\%) and had no further clinical relevance. In addition, the prevalence of conduction disturbances was similar in both groups, with little clinical relevance, respectively $23 \%$ vs. $24 \%$. The prevalence of AVR was significantly higher in AS patients compared to the controls, respectively $23 \%$ (9\% trace, $12 \%$ mild, $1 \%$ moderate, $1 \%$ severe, $1 \%$ prosthesis) vs. $11 \%, p=0.04$. After correcting for age, sex and CV risk factors, AS patients had an odds ratio of 4.5 ( $95 \%$ CI 1.1-13.6) for AVR compared to the controls. In contrast, the prevalence values of MVR were similar and mostly not clinically relevant in AS patients and controls, respectively $36 \%$ and $32 \%$ and $p=0.46$. Conclusion: The prevalence of diastolic LV dysfunction and conduction disorders was mostly not clinically relevant, and similar in AS patients and controls. However, AS patients had an up to five times increased odds to develop AVR compared to controls. Therefore, echocardiographic screening of elderly (50-75 years) AS patients should be considered.

Keywords: ankylosing spondylitis; cardiovascular disease; left ventricular function; cardiac conduction disturbances; transthoracic echocardiography

\section{Introduction}

Ankylosing spondylitis (AS) is an inflammatory joint disease associated with extraarticular manifestations, including cardiac disease [1,2]. Previous studies have shown an increased mortality in AS patients compared to the general population, with cardiovascular diseases as the leading cause of death [3,4]. Chronic inflammation in AS contributes 
considerably to this excess cardiovascular risk; besides progression of atherosclerosis, it may lead to structural changes of the heart, thereby causing cardiac disease $[5,6]$. Indeed, previous studies suggest that AS patients are at increased risk to develop aortic valve regurgitation (AVR), conduction disorders and diastolic left ventricular (LV) dysfunction. Although some of the previous studies suggested that these cardiac manifestations occur more frequently in AS patients, results varied and are altogether inconclusive [7-15]. Furthermore, therapeutic treatment in AS has significantly improved in the last decades and this may have altered the $\mathrm{CV}$ burden. As recent data regarding the prevalence of cardiac manifestations in AS are lacking, clear guidelines regarding cardiovascular screening of AS patients are still absent. Hence, current cardiovascular risk management guidelines make no distinction between AS patients and healthy persons, and the EULAR only recommends to perform a CVD risk assessment once every 5 years [16]. Therefore, the aim of the present study was to determine the current prevalence of diastolic LV dysfunction (primary objective), cardiac valve regurgitation and conduction disorders (secondary objectives) in a large cohort of AS patients, and compare these results to findings in controls without an inflammatory joint disease, i.e., osteoarthritis (OA) patients. As cardiac disease is more prominent with older age, we assessed the prevalence of cardiac disease in subjects between 50 and 75 years.

\section{Materials and Methods}

\subsection{Study Population}

A cross-sectional controlled study was conducted in randomly selected AS patients and age, sex and smoking status matched controls in a 2:1 ratio. Control patients with OA were selected as they also suffer from joint problems and subsequent mobility issues (physical activity), however without auto-inflammatory characteristics. Subjects were randomly recruited between March 2014 and February 2020 at a large rheumatology outpatient clinic (Reade) in Amsterdam, the Netherlands. Patients were eligible for inclusion if they were between 50 and 75 years of age. AS patients needed to be diagnosed according to the 1984 modified New York [17] criteria and OA controls with active hip-, knee- or polyosteoarthritis had to be diagnosed by a general practitioner or rheumatologist. Patients with a history of chemotherapy (for malignant disease) were excluded due to the presence of potential cardiotoxicity. All patients provided written consent prior to inclusion in the study. This study was conducted in accordance with the Helsinki Declaration, and the protocol (NL44202.048.13) was approved by the medical ethics committee of the Slotervaart hospital and Reade, Amsterdam, the Netherlands.

\subsection{Echocardiography}

Transthoracic echocardiography (TTE) was performed by certified echo technicians at the European Society of Cardiology (ESC)-certified department of echocardiography of the Amsterdam University medical center, location VUmc, using a Philips ultrasound system (Epiq 7 or IE 33). Furthermore, the echo technicians were not informed about the clinical diagnosis of the subject. To exclude inter-observer variability, all recordings of echocardiographic images and data were assessed afterwards by an experienced cardiologist of the VUmc specialized in echocardiography (T.K.). The cardiologist graded diastolic dysfunction, AVR and MVR. TTE was performed according to the guidelines provided by the American Society of Echocardiography (ASE) and the European Association of Cardiovascular Imaging (EACVI) (see Appendix A) [18]. Furthermore, the severity of AVR and MVR was graded according to the EACVI guidelines $[19,20]$. Left atrial volume (LA volume, $\mathrm{mL}$ ) index and left ventricular mass (LVM, $\mathrm{g}$ ) index were calculated with body surface area $\left(\mathrm{BSA}, \mathrm{m}^{2}\right) \mathrm{LA}$ volume or $\mathrm{LVM} / \mathrm{BSA}\left(\mathrm{g} / \mathrm{m}^{2}\right)$. The aortic root was measured at sinuses of Valsalva during diastole. Furthermore, aortic root diameter was corrected for BSA according to the Dubois method (aortic root index) [21]. An aortic root index of $\geq 2.1 \mathrm{~cm} / \mathrm{m}^{2}$ was considered as aortic root dilatation [22,23]. 


\subsection{Electrocardiography}

Electrocardiography (ECG) was performed using standard 12-lead ECGs, recorded at a $25 \mathrm{~mm} / \mathrm{s}$ paper speed. ECGs were analyzed by a single cardiologist (T.K.), who was blinded to the clinical status of all patients.

\subsection{Disease-Specific Parameters}

The following disease-specific parameters were collected. In AS: HLA-B27 status, extra-articular manifestations and disease activity (Bath AS Metrology Index (BASMI), Bath AS Disease Activity Index (BASDAI) and AS Disease Activity Score-C-reactive protein (ASDAS-CRP)). In AS, high disease activity was defined as an ASDAS score of $\geq 2$.1. In OA, disease severity was assessed with the Western Ontario and McMaster Universities Osteoarthritis index (WOMAC) questionnaire [24].

\subsection{Cardiovascular History and Risk Factor Parameters}

Cardiovascular risk factors were assessed including smoking status, body mass index (BMI), hypertension, hypercholesterolemia, diabetes mellitus type II and family history for cardiovascular disease. Furthermore, data history for cardiovascular disease was collected, i.e., angina pectoris, myocardial infarction, congestive heart failure, stroke (cerebrovascular accident (CVA) and/or transient ischemic attack (TIA)), peripheral ischemia and coronary arterial bypass grafting (CABG).

\subsection{Other Study Parameters}

Anthropometric data including length, weight, waist/hip ratio and blood pressure were assessed during physical examination. Demographic data were collected, i.e., age, race, ethnicity and sex. Blood sample measurements (non-fasting) consisted of standard hematological assessment, erythrocyte sedimentation rate (ESR), CRP, triglyceride, total cholesterol, high-density lipoprotein (HDL), low-density lipoprotein (LDL) and HLA-B27 status. Furthermore, medical history, current and historic medication use and diseasespecific data (i.e., year of onset, disease duration) were documented.

\subsection{Definitions}

\subsubsection{Systolic LV Dysfunction}

Systolic LV dysfunction was defined as a left ventricular ejection fraction (LVEF) less than $50 \%$.

\subsubsection{Diastolic LV Dysfunction}

Diastolic LV dysfunction was evaluated according to the 2009 ASE/EACVI recommendations and 2016 ASE/EACVI recommendations, and both were categorized in 4 grades: normal diastolic LV function and grade I-III (or intermediate) [25,26]. Regarding the 2016 ASE/EACVI recommendations, for patients with a preserved ejection fraction, four variables were evaluated: average mitral E/ $\mathrm{e}^{\prime}$ velocity, septal and lateral $\mathrm{e}^{\prime}$ velocity, tricuspid regurgitation velocity (TR-velocity, $\mathrm{cm} / \mathrm{s}$ ) and LA volume index. Patients with at least three aberrant values were diagnosed with diastolic LV dysfunction. Patients with more than one missing variable were not classified.

\subsubsection{Hypertension}

Patients were diagnosed with hypertension when they had a systolic blood pressure $\geq 140 \mathrm{mmHg}$ or diastolic blood pressure $\geq 90 \mathrm{mmHg}$, measured during the physical examination, or when they were using antihypertensive medication.

\subsubsection{Family History}

A positive family history for cardiovascular events or cerebrovascular events was defined as having a first-degree female relative under 65 years old or a male relative 
under 55 years old diagnosed with angina pectoris/myocardial infarction or TIA/CVA, respectively.

\subsubsection{Cardiovascular Diseases}

A positive history of cardiovascular disease was defined as a history of angina pectoris, myocardial infarction, coronary artery bypass grafting (CABG), congestive heart failure, CVA/TIA and/or peripheral ischemia.

\subsubsection{Obesity}

Obesity is defined as a BMI $\geq 30 \mathrm{~kg} / \mathrm{m}^{2}$.

\subsubsection{Statistical Analysis}

Continuous variables are expressed as mean \pm standard deviation (SD) for normally distributed variables or median (interquartile range) for non-normally distributed variables. Differences were compared between subjects using the independent samples $t$-test for normally distributed variables and the Mann-Whitney U test for non-normally distributed variables. Dichotomous and categorical data are presented as frequencies (percentages). These variables were compared using a Chi-square test or Fisher's exact test where applicable.

Logistic multivariate regression analyses were performed to investigate the association between AS and valve regurgitation. In addition, subgroup analyses using linear or logistic multivariate regression analyses were performed to investigate the relationship of disease duration, disease activity and anti-tumor necrosis factor (TNF) with valve regurgitation. All statistical analyses were performed using SPSS software (version 23.0, Chicago, IL, USA).

\section{Results}

\subsection{Patient Characteristics}

Baseline characteristics are shown in Table 1. A total of 193 AS patients and 74 matched controls were included in the study. Matching was performed in the best way possible within logistical limitations. The mean age of the AS patients and the controls was respectively $60( \pm 7)$ years and $62( \pm 7)$ years, and $72 \%$ and $58 \%$ were male, respectively. AS patients had a lower BMI and BSA than controls, respectively $26.6 \pm 4.1 \mathrm{vs} .28 .6 \pm 5.5 \mathrm{~kg} / \mathrm{m}^{2}$ and $1.9 \pm 0.20$ vs. $2.0 \pm 0.2 \mathrm{~m}^{2}$. Furthermore, obesity and hypercholesterolemia were seen less often in AS patients compared to controls, respectively $22 \%$ vs. $30 \%$ and $19 \%$ vs. $30 \%$. AS patients used more antihypertensives compared to controls, respectively $44 \%$ vs. $27 \%$. The prevalence of other cardiovascular diseases, comorbidities and risk factors were comparable in both groups.

Table 1. Patient characteristics of AS and OA controls.

\begin{tabular}{ccc}
\hline & AS Patients $(\boldsymbol{n}=\mathbf{1 9 3})$ & OA Controls $(\boldsymbol{n}=\mathbf{7 4 )}$ \\
\hline Patient characteristics & & \\
\hline Gender, male $(n, \%)$ & $138(72)$ & $43(58)$ \\
Age, years (mean \pm SD) & $60 \pm 7$ & $62 \pm 7$ \\
Race, Caucasian $(n, \%)$ & $162(84)$ & $65(88)$ \\
BMI, kg/m ${ }^{2}$ (mean \pm SD) & $26.6 \pm 4.1$ & $2.0 \pm 0.5$ \\
BSA, m ${ }^{2}$ (mean \pm SD) & $1.9 \pm 0.2$ & $133 \pm 17$ \\
Blood pressure, mmHg & & $82 \pm 9$ \\
Systolic (mean \pm SD) & $134 \pm 16$ & $8.2 \pm 8$ \\
Diastolic (mean \pm SD) & $84 \pm 8$
\end{tabular}


Table 1. Cont.

\begin{tabular}{|c|c|c|}
\hline & AS Patients $(n=193)$ & OA Controls $(n=74)$ \\
\hline \multicolumn{3}{|l|}{ CVD risk factors } \\
\hline \multicolumn{3}{|l|}{ Smoking status } \\
\hline current $(n, \%)$ & $39(20)$ & $15(20)$ \\
\hline ever $(n, \%)$ & $98(51)$ & $35(47)$ \\
\hline never $(n, \%)$ & $55(29)$ & $24(32)$ \\
\hline pack years (median, IQR) & $28(14-37)$ & $12(6-31)$ \\
\hline Obesity $(n, \%)$ & $42(22)$ & $26(35)$ \\
\hline Hypertension $(n, \%)$ & $118(61)$ & $45(61)$ \\
\hline Hypercholesterolemia $(n, \%)$ & $36(19)$ & $22(30)$ \\
\hline Diabetes Mellitus type II $(n, \%)$ & $22(11)$ & $10(14)$ \\
\hline Total history CVD $(n, \%)$ & $21(11)$ & $8(11)$ \\
\hline Angina Pectoris $(n, \%)$ & $5(3)$ & $2(3)$ \\
\hline Myocardial infarction $(n, \%)$ & $12(6)$ & $4(5)$ \\
\hline \multicolumn{3}{|l|}{ Stroke } \\
\hline TIA $(n, \%)$ & $4(2)$ & $3(4)$ \\
\hline $\operatorname{CVA}(n, \%)$ & $3(2)$ & $0(0)$ \\
\hline Peripheral ischemia $(n, \%)$ & $1(1)$ & $1(1)$ \\
\hline CABG $(n, \%)$ & $8(4)$ & $2(3)$ \\
\hline \multicolumn{3}{|l|}{ Family history (first degree) } \\
\hline $\operatorname{AP} / \mathrm{MI}(n, \%)$ & $24(12)$ & $11(15)$ \\
\hline Stroke/TIA $(n, \%)$ & $14(7)$ & $6(8)$ \\
\hline \multicolumn{3}{|l|}{ Laboratory } \\
\hline $\mathrm{LDL}, \mathrm{mmol} / \mathrm{L}$ & $3.3 \pm 0.9$ & $3.5 \pm 1.1$ \\
\hline $\mathrm{HDL}, \mathrm{mmol} / \mathrm{L}$ & $1.5 \pm 0.4$ & $1.3 \pm 0.4$ \\
\hline Cholesterol/HDL ratio & $3.8 \pm 1.6$ & $4.2 \pm 1.7$ \\
\hline $\mathrm{ESR}, \mathrm{mm} / \mathrm{h}$ & $7.5(4.0-10.0)$ & $5.0(2.0-11)$ \\
\hline $\mathrm{CRP}, \mathrm{mg} / \mathrm{L}$ & $2.8(1.1-7.8)$ & $1.6(0.8-3.1)$ \\
\hline \multicolumn{3}{|l|}{ Medication } \\
\hline Antihypertensives $(n, \%)$ & $85(44)$ & $20(27)$ \\
\hline Lipid-modifying drugs $(n, \%)$ & $40(21)$ & $19(26)$ \\
\hline NSAIDs $(n, \%)$ & $108(56)$ & $37(50)$ \\
\hline \multicolumn{3}{|l|}{ Anti-TNF drugs } \\
\hline current $(n, \%)$ & $70(36)$ & N.A. \\
\hline ever $(n, \%)$ & $13(7)$ & N.A. \\
\hline naive $(n, \%)$ & $110(57)$ & N.A. \\
\hline
\end{tabular}

Values are displayed as mean \pm standard deviation (SD), median with corresponding interquartile range (IQR) or frequencies with corresponding percentages (\%). AS = ankylosing spondylitis, $\mathrm{OA}=$ osteoarthritis, $\mathrm{BMI}=$ body mass index, $\mathrm{BSA}=$ body surface area, $\mathrm{CVD}=$ cardiovascular disease, $\mathrm{TIA}=$ transient ischemic attack, $\mathrm{CVA}=$ cerebrovascular attack, $\mathrm{CABG}=$ coronary artery bypass graft, $\mathrm{AP}=$ angina pectoris, $\mathrm{MI}=\mathrm{my}-$ ocardial infarction, NSAIDs $=$ non-steroidal anti-inflammatory drugs, anti-TNF $=$ anti-tumor necrosis factor, N.A. = not applicable. Normal ranges for laboratory assessments: LDL 2.0-4.5 mmol/L, HDL 0.9-1.7 mmol/L, ESR in men $>50$ years $<20 \mathrm{~mm} / \mathrm{h}, \mathrm{ESR}$ in women $>50$ years $<30 \mathrm{~mm} / \mathrm{h}, \mathrm{CRP}<10 \mathrm{mg} / \mathrm{L}$.

\subsection{Disease Characteristics}

Disease characteristics are shown in Table 2. A total of $82 \%$ of the AS patients were HLA-B27+. AS patients had a moderate to high disease activity with a mean ASDAS-CRP of $2.1( \pm 1.0)$ and a mean disease duration of $22( \pm 12)$ years. Most of the OA controls had knee osteoarthritis (82\%) and/or poly-osteoarthritis (81\%) compared to hip osteoarthritis $(24 \%)$. Disease duration (since diagnosis) was $5(2-8)$ years. OA patients had a median WOMAC score of $42( \pm 23)$. 
Table 2. Disease characteristics of AS and OA controls.

\begin{tabular}{cc}
\hline Ankylosing Spondylitis & $n=\mathbf{1 9 3}$ \\
\hline HLA-B27-positive $(n, \%)$ & $156(82)$ \\
Disease activity and severity & $2.1 \pm 1.0$ \\
ASDAS-CRP (mean \pm SD) & $4.1 \pm 1.8$ \\
BASMI (mean \pm SD) & $3.7 \pm 2.4$ \\
BASFI (mean \pm SD) & $3.1(1.6-5.0)$ \\
BASDAI (median; IQR) & $22 \pm 12$ \\
\hline Time since diagnosis, years (mean \pm SD) & $n=74$ \\
\hline Osteoarthritis & \\
Affected joints & $61(82)$ \\
Knee $(n, \%)$ & $18(24)$ \\
Hip $(n, \%)$ & $60(81)$ \\
Poly-osteoarthritis $(n, \%)$ & $15(20)$ \\
Prosthesis $(n, \%)$ & $42(23)$ \\
WOMAC (mean \pm SD) & $5(2-8)$ \\
\hline Time since diagnosis (median; IQR)
\end{tabular}

Values are displayed as mean \pm standard deviation (SD), median with corresponding interquartile range (IQR) or frequencies with corresponding percentages (\%). AS = ankylosing spondylitis, OA = osteoarthritis, HLA = Human leukocyte antigen, ASDAS-CRP = Ankylosing Spondylitis Disease Activity Score-C-reactive protein, BASMI = Bath Ankylosing Spondylitis Metrology Index, BASFI = Bath Ankylosing Spondylitis Functional Index, BASDAI = Bath Ankylosing Spondylitis Disease Activity Index, WOMAC $=$ Western Ontario and McMaster Universities Osteoarthritis.

\subsection{Electrocardiography}

Electrocardiographic results are shown in Table 3. No differences were found in conduction disorders between AS patients and controls.

Table 3. Electrocardiographic results.

\begin{tabular}{|c|c|c|c|}
\hline & $\begin{array}{l}\text { AS Patients } \\
\quad(n=193)\end{array}$ & $\begin{array}{l}\text { OA Controls } \\
\quad(n=74)\end{array}$ & $p$-Value ${ }^{\text {a }}$ \\
\hline Atrial fibrillation $(n, \%)$ & $3(2)$ & $4(5)$ & 0.10 \\
\hline Atrial flutter $(n, \%)$ & $0(0)$ & $0(0)$ & 1.0 \\
\hline \multicolumn{4}{|l|}{ AV-block } \\
\hline 1st degree $(n, \%)$ & $2(1)$ & $1(1)$ & 0.62 \\
\hline 2nd degree, Mobitz type $1(n, \%)$ & $0(0)$ & $0(0)$ & 1.0 \\
\hline 2nd degree, Mobitz type $2(n, \%)$ & $0(0)$ & $0(0)$ & 1.0 \\
\hline 3rd degree $(n, \%)$ & $0(0)$ & $0(0)$ & 1.0 \\
\hline $\operatorname{LBBB}(n, \%)$ & $2(1)$ & $0(0)$ & 1.0 \\
\hline $\operatorname{LAFB}(n, \%)$ & $2(1)$ & $0(0)$ & 1.0 \\
\hline $\operatorname{RBBB}(n, \%)$ & $2(1)$ & $3(4)$ & 1.0 \\
\hline $\operatorname{iRBBB}(n, \%)$ & $13(7)$ & $5(7)$ & 1.0 \\
\hline Pathologic $\mathrm{Q}$ waves $(n, \%)$ & $3(2)$ & $4(5)$ & 0.10 \\
\hline $\operatorname{LVH}(n, \%)$ & $9(5)$ & $0(0)$ & 0.11 \\
\hline Nonspecific IVCD $(n, \%)$ & $2(1)$ & $1(1)$ & 1.0 \\
\hline Pacemaker $(n, \%)$ & $2(1)$ & $0(0)$ & 1.0 \\
\hline Other $(n, \%)$ & $5(3)$ & $0(0)$ & 0.33 \\
\hline Total $(n, \%)$ & $44(23)$ & $18(24)$ & \\
\hline
\end{tabular}

Values are displayed as frequencies with corresponding percentages (\%). AS = ankylosing spondylitis, OA = osteoarthritis, $\mathrm{AV}$ block = atrioventricular block, $\mathrm{LBBB}=$ left bundle branch block, $\mathrm{LAFB}=$ left anterior fascicular block, $\mathrm{RBBB}=$ right bundle branch block, $\mathrm{iRBBB}=$ incomplete right bundle branch block, $\mathrm{LVH}=$ left ventricular hypertrophy, IVCD = intraventricular conduction delay. ${ }^{\text {a }} p$-values of chi-square test.

\subsection{Echocardiography}

Table 4 provides an overview of echocardiographic parameters. An increased aortic root index was seen in AS patients compared to controls, though both in the normal range, respectively $1.74( \pm 0.20) \mathrm{cm} / \mathrm{m}^{2}$ vs. $1.68( \pm 0.22) \mathrm{cm} / \mathrm{m}^{2}, p=0.08$. The prevalence of aortic 
root dilatation $\left(\geq 2.1 \mathrm{~cm} / \mathrm{m}^{2}\right)$ was comparable in both groups, with a prevalence of $7 \%$ in AS patients and $4 \%$ in controls, $p=0.53$. Furthermore, AS patients had AVR more often compared to controls, $41(23 \%)$ vs. $8(11 \%), p=0.04$. No difference was observed in MVR between AS patients and controls. The prevalence of systolic and diastolic LV dysfunction (both 2009 and 2016 ESE/EACVI grading criteria) was low and comparable between AS patients and controls.

Table 4. Echocardiographic results.

\begin{tabular}{|c|c|c|c|}
\hline Cardiac Structures & $\begin{array}{l}\text { AS Patients } \\
\quad(n=193)\end{array}$ & $\begin{array}{c}\text { OA Controls } \\
\quad(n=74)\end{array}$ & $p$-Value ${ }^{a}$ \\
\hline Aortic root index, $\mathrm{cm} / \mathrm{m}^{2}($ mean $\pm \mathrm{SD})$ & $1.74 \pm 0.20$ & $1.68 \pm 0.22$ & 0.08 \\
\hline Aortic root dilatation, $\geq 2.1 \mathrm{~cm} / \mathrm{m}^{2}(n, \%)$ & $12(7)$ & $2(4)$ & 0.53 \\
\hline \multicolumn{4}{|l|}{ ** Mitral valve regurgitation } \\
\hline Mild $(n, \%)$ & $65(34)$ & $23(32)$ & \multirow{4}{*}{0.46} \\
\hline Moderate $(n, \%)$ & $4(2)$ & $0(0)$ & \\
\hline Severe $(n, \%)$ & $0(0)$ & $0(0)$ & \\
\hline Prosthesis $(n, \%)$ & $0(0)$ & $0(0)$ & \\
\hline \multicolumn{4}{|l|}{ Aortic valve regurgitation } \\
\hline Trace $(n, \%)$ & $16(9)$ & $1(1)$ & \multirow{5}{*}{$0.04 *$} \\
\hline Mild $(n, \%)$ & $23(12)$ & $7(10)$ & \\
\hline Moderate $(n, \%)$ & $1(1)$ & $0(0)$ & \\
\hline Severe $(n, \%)$ & $1(1)$ & $0(0)$ & \\
\hline Prosthesis $(n, \%)$ & $1(1)$ & $0(0)$ & \\
\hline \multicolumn{4}{|l|}{ Cardiac function } \\
\hline LV mass index, $\mathrm{g} / \mathrm{m}^{2}($ mean $\pm \mathrm{SD})$ & $75 \pm 20$ & $76 \pm 19$ & 0.79 \\
\hline LA volume index, $\mathrm{mL} / \mathrm{m}^{2}($ mean $\pm \mathrm{SD})$ & $29 \pm 9$ & $32 \pm 13$ & 0.11 \\
\hline $\mathrm{EDV}$ index, $\mathrm{mL} / \mathrm{m}^{2}($ mean $\pm \mathrm{SD})$ & $62 \pm 15$ & $55 \pm 18$ & 0.01 * \\
\hline ESV index, $\mathrm{mL} / \mathrm{m}^{2}($ mean $\pm \mathrm{SD})$ & $27 \pm 8$ & $22 \pm 10$ & $<0.01 *$ \\
\hline Ejection fraction (mean $\pm \mathrm{SD})$ & $57 \pm 6$ & $60 \pm 8$ & $0.02 *$ \\
\hline $\mathrm{E} / \mathrm{e}^{\prime}$ average, $\mathrm{cm} / \mathrm{s}($ mean $\pm \mathrm{SD})$ & $8.5 \pm 2.5$ & $8.0 \pm 2.1$ & 0.16 \\
\hline $\mathrm{E}-\mathrm{max}, \mathrm{cm} / \mathrm{s}($ mean $\pm \mathrm{SD})$ & $69 \pm 17$ & $65 \pm 17$ & 0.06 \\
\hline A-max, cm/s (mean $\pm \mathrm{SD})$ & $71 \pm 17$ & $71 \pm 17$ & 0.95 \\
\hline $\mathrm{E} / \mathrm{A}$ ratio $($ mean $\pm \mathrm{SD})$ & $1.0 \pm 0.3$ & $0.9 \pm 0.2$ & 0.03 * \\
\hline MV deceleration time, $\mathrm{m} / \mathrm{s}$ (mean $\pm \mathrm{SD}$ ) & $0.22 \pm 0.05$ & $0.22 \pm 0.04$ & 0.83 \\
\hline Septal e' velocity, $\mathrm{cm} / \mathrm{s}($ mean $\pm \mathrm{SD})$ & $7.8 \pm 1.9$ & $7.4 \pm 1.7$ & 0.12 \\
\hline Lateral $\mathrm{e}^{\prime}$ velocity, $\mathrm{cm} / \mathrm{s}($ mean $\pm \mathrm{SD})$ & $9.5 \pm 2.7$ & $9.5 \pm 2.2$ & 0.94 \\
\hline TR velocity, $\mathrm{cm} / \mathrm{s}($ mean $\pm \mathrm{SD})$ & $219 \pm 26$ & $229 \pm 30$ & 0.23 \\
\hline Systolic LV dysfunction $(n, \%)$ & $10(5)$ & $2(3)$ & 0.74 \\
\hline \multicolumn{4}{|l|}{ Diastolic LV dysfunction-2016 } \\
\hline Grade I $(n, \%)$ & $6(3)$ & $2(3)$ & \multirow{3}{*}{0.88} \\
\hline Grade II $(n, \%)$ & $1(1)$ & $0(0)$ & \\
\hline Grade III $(n, \%)$ & $0(0)$ & $0(0)$ & \\
\hline \multicolumn{4}{|l|}{ Diastolic LV dysfunction-2009 } \\
\hline Grade I $(n, \%)$ & $60(32)$ & $17(25)$ & \multirow{3}{*}{0.59} \\
\hline Grade II $(n, \%)$ & $39(21)$ & $16(24)$ & \\
\hline Grade III $(n, \%)$ & $0(0)$ & $0(0)$ & \\
\hline
\end{tabular}

Values are displayed as mean \pm standard deviation (SD) or frequencies with corresponding percentages (\%) Indexed values are corrected for BSA. AS = ankylosing spondylitis, OA = osteoarthritis, BSA = body surface index, $\mathrm{LVMI}=$ left ventricle mass index, $\mathrm{LV}=$ left ventricular, $\mathrm{EDV}=$ end diastolic volume, $\mathrm{ESV}=\mathrm{end}$ systolic volume, $\mathrm{MV}=$ mitral valve, $\mathrm{TR}=$ tricuspid regurgitation. ${ }^{\mathrm{a}} p$-values of Student's $t$-test or chi-square test. ${ }^{*}$ Bold significance level of $p \leq 0.05$. ${ }^{* *}$ A trace MVR is considered as physiological regurgitation and is therefore not added in the table.

\subsection{Results of Regression Analyses}

Results of logistic multivariate regression analyses are presented in Table 5. The relationship between AVR and AS was statistically significant and became more pronounced after adjusting for age, sex and CV risk factors. It revealed that AS patients had an increased odds of AVR compared to controls (OR: 4.5; 95\% CI: 1.1-13.6). In contrast, AS patients did not have an increased odds of MVR compared to controls (OR: 1.9; 95\% CI: 0.8-4.5). Lastly, 
subgroup analyses in AS showed no significant relationship between disease duration, ASDAS-CRP and anti-TNF drugs and the presence of AVR or MVR.

Table 5. Association of AS with valve regurgitation.

\begin{tabular}{|c|c|c|c|}
\hline & Crude Model & Adjusted Model a & $\begin{array}{l}\text { Fully Adjusted } \\
\text { Model }\end{array}$ \\
\hline Aortic valve regurgitation & $2.3(1.0-5.3) *$ & $2.9(1.3-6.8) *$ & $4.5(1.1-13.6) *$ \\
\hline Mitral valve regurgitation & $1.2(0.7-2.2)$ & $1.4(0.8-2.5)$ & $1.9(0.8-4.5)$ \\
\hline
\end{tabular}

Values are displayed as odds ratio with corresponding $95 \%$ confidence interval. ${ }^{\text {a }}$ Adjusted for age and gender

$\mathrm{b}$ Adjusted for age, gender, current smoking status, pack years, systolic blood pressure, diastolic blood pressure, hypercholesterolemia, BMI, Diabetes Mellitus type 2, family history of cardiovascular diseases. * Significance level of $p \leq 0.05$.

\section{Discussion}

The results of this study revealed that diastolic LV dysfunction, based on the 2016 criteria of the ASE/EACVI, was rare in both AS patients and controls, and the prevalence was comparable for both groups. Equally, the prevalence of conduction disorders was similar in both groups and mostly not clinically relevant. In contrast, AS patients had an up to five times increased odds of AVR compared to OA controls. Disease activity, disease duration and use of TNF-inhibitors were not associated with AVR.

\subsection{Diastolic LV Dysfunction}

It is hypothesized that development of diastolic LV dysfunction may result from coronary endothelium activation caused by systemic inflammation [27]. The activated endothelial cells cause cardiomyocytes to hypertrophy and stiffen, but also enable monocytes to enter cardiac tissue, where they trigger collagen production. The combined effect of these processes may lead to microvascular rarefaction, interstitial fibrosis and stiff cardiomyocytes, which impairs relaxation of the ventricles and thus induces diastolic LV dysfunction $[27,28]$.

The current literature supports evidence for an increased risk of diastolic LV dysfunction in AS patients, albeit that varying prevalence rates have been reported $(9-45 \%)[14,15]$. Three studies assessed diastolic LV dysfunction using the combined set of parameters as recommended by the ASE/EACVI in 2009, ranging from $12 \%$ to $45 \%$, though cut-off values of single parameters differed slightly between studies $[15,29,30]$. Other studies reported prevalence rates ranging from $20 \%$ to $49 \%$, but those studies were not specifically designed to assess diastolic LV dysfunction or only used a single or few echocardiographic parameters for assessing diastolic LV dysfunction, which differs from the ASE/EACVI guidelines $[8,14,26,31-34]$. Nowadays, the most appropriate way, recommended by American and European echocardiography organizations (ASE and EACVI), to assess diastolic $\mathrm{LV}$ dysfunction, is to combine specific echocardiographic parameters [35].

However, the 2009 algorithms were considered too complex and had a substantial interobserver variability, which possibly caused the wide variation in the observed prevalence of diastolic LV dysfunction. Therefore, the guidelines to assess diastolic LV dysfunction were upgraded in 2016 by the ASE/EACVI with the purpose of simplifying the approach [36]. It has been shown that the 2016 algorithm is superior to the 2009 algorithm with regards to specificity, correlation with clinical outcomes and inter-observer variability, but had a lower sensitivity [37]. Thus far, there have been no studies assessing diastolic LV function in AS patients with the updated ASE/EACVI 2016 guidelines. The above-mentioned studies mostly used the 2009 criteria, and when using the 2009 algorithm, we found a prevalence of diastolic LV dysfunction of $53 \%$ in AS patients and $46 \%$ in OA patients, respectively. When applying the 2016 criteria, these prevalence rates declined to $3.8 \%$ and $3.3 \%$, respectively. Moreover, eight of the nine patients with diastolic LV dysfunction also had systolic LV dysfunction. According to the 2016 criteria, all patients with systolic LV dysfunction are defined to have also diastolic LV dysfunction. For our study, this means that only one patient in the entire cohort was diagnosed with diastolic LV dysfunction because of 
aberrant echocardiographic Doppler values. Altogether, our results indicate that diastolic $\mathrm{LV}$ dysfunction in AS patients is infrequent and that previous studies overestimated the prevalence of impaired diastolic LV function in AS patients due to the low accuracy of the diagnostic/grading tool.

\subsection{Conduction Disorders}

Major electrical conduction elements, such as the atrial-ventricular (AV) node and the bundle branches (BBs), are located in very close proximity to the heart valves. In addition to the aortic root and the cusps of the aortic valve, in AS, the inflammatory process therefore may extend to the atrial ventricular node (AV-node) and interventricular septum, leading to AR, AV-blocks and bundle branch blocks (BBB's) [38]. However, most of the existing studies regarding conduction disturbances in AS patients were relatively small, and some lack controls and the results are inconsistent $[8,11,12,39,40]$. Our study assessed the clinically relevant and significant conduction disturbances in a large cohort of AS patients. We found a very low prevalence of, mostly mild, conduction disturbances with limited clinical relevance in the AS population comparable to the controls, which is in contrast to the existing literature $[11,12,39]$. A Swedish prospective, nationwide populations-based cohort showed that AS patients have a two-fold increased risk to develop an AV-block. However, the clinical relevance of this result is limited as this corresponds with an AV-block prevalence of $0.5 \%$ in AS patients compared to $0.4 \%$ in healthy subjects after a follow-up duration of 6 years [11]. Two other studies performed by Forsblad-d'Elia et al. and Dik et al. demonstrated in clinical trials that first-degree AV-blocks and BBB's are common in AS patients [12,39]. However, both studies had no control group to compare their results to, and after specifying the type of BBB, the total prevalence of BBB's dropped under $10 \%$, with both studies reporting primarily incomplete BBB's. In fact, Dik et al. demonstrated only $0.8 \%$ (1) of the AS patients with a complete right $\mathrm{BBB}$, and none with a complete left BBB or left hemi block [39], though, their subjects were younger. Therefore, based on our results and in the context of the existing literature, we conclude that conduction disturbances are mostly mild with limited clinical relevance, and conduction disorders do not occur more frequently in AS patients compared to controls.

\subsection{Aortic Valve Regurgitation}

We found a prevalence of $23 \%$ of AVR in AS patients and thus a 4-5 times increased odds for AVR in comparison to controls. Previous echocardiographic studies showed varying prevalence rates of AVR in AS patients, ranging from $6 \%$ to $31 \%[6,8-10,38,40]$. However, as the presence of AVR is associated with age and cardiovascular risk factors, and these differed greatly between the available studies, these prevalence data are not very comparable. Overall, the AS patients of these cohort studies were younger, had a shorter disease duration and one study did not include trace AVR, thus likely underestimating the prevalence of AVR. Brunner et al. observed that AVR was present in $10 \%$ of AS patients, but they included patients aged 32-86 years and did not assess CV risk factors or comorbidities [8]. Again, trace regurgitation was not taken into account, likely leading to a considerable underestimation of the prevalence.

Our most important observation was that elderly AS patients (50-75 years) have an up to five times increased odds of having AVR compared to controls after correction for age, sex and CV risk factors. In addition, OA patients have an increased CV burden due to increased CV comorbidities, and the increased risk that we observed in AS patients is probably an underestimation compared to when healthy subjects would have been used as controls [22].

In this study, we observed a significant difference in the prevalence of AV regurgitation between AS patients and controls, but manifestations were mostly mild. Nevertheless, chronic AVR is a slow progressive disease, and the chronic state of inflammation that is present in AS patients may further accelerate progression. Moreover, the American Heart Association/American College of Cardiology (AHA/ACC) and the European Association 
of Cardiovascular Imaging (EACVI) state that regurgitation of the aortic valve is pathological, regardless of its grade [41,42]. Hence, echocardiographic follow-up once per 3-5 years for trace or mild regurgitation, once per 1-2 years for moderate regurgitation and once per $0.5-1$ year for severe regurgitation is recommended. Severe AR and rapid progression of the disease can be treated by valve replacement if recognized timely.

The current hypothesis on the valve involvement in AS is that entheses, the region where ligaments and tendons attach to bones, are the structures where inflammatory processes in AS mainly take place [43]. Pro-inflammatory cytokines, such as Interleukin (IL)- 23 and IL-17, have an important role in this inflammatory process, and IL-23 stimulates IL-17 production by Th17 cells, which further amplifies this inflammation [44-46]. The relevance for cardiac involvement in AS is that entheses and the part of the aortic valve that inserts into the aortic root are histologically similar [46]. Sherlock et al. demonstrated in mice that both entheses and this part of the aortic root contain IL-23 receptor-positive T-cells that can induce local inflammation after systemic exposure to IL-23 [46]. In the aortic root, inflammation may cause root dilatation and the inflammation may extend to the annulus, resulting in basal thickening and downward retraction of the cusps, also resulting in AVR $[38,47,48]$. The thickening of the annulus itself could also disturb the laminar blood flow, resulting in deterioration of valve function. In line with the increased prevalence of AVR in AS patients, we observed a trend towards a significantly greater aortic root index compared to OA controls, respectively $1.74 \pm 0.20 \mathrm{~cm} / \mathrm{m}^{2}$ vs. $1.68 \pm 0.22 \mathrm{~cm} / \mathrm{m}^{2}$, $p=0.08$. This is consistent with small-sized studies of Roldan et al. and Yildirir et al., as they also showed increased aortic root diameter, as well as increased prevalence of AVR in AS patients compared to controls [38,49].

\subsection{Strengths and Limitations}

Our study has several strengths and limitations. First, to our knowledge, this is the largest study undertaken in AS patients assessing LV function by echocardiography. Second, this is the first study to assess diastolic LV dysfunction in AS patients based on the 2016 guidelines of the ASE/EACVI.

There are also limitations of the present study. First of all, due to the cross-sectional study design, the associations found in this study are not necessarily causal. We were therefore unable to determine long-term consequences of the cardiac manifestations we observed in our patients. Secondly, complete matching of groups on a ratio of 2:1 based on age, sex and current smoking status was not completely achieved, introducing minor differences in patient characteristics. Therefore, we adjusted for these variables in our regression analyses, thereby limiting the consequences thereof.

\section{Conclusions}

Against our expectations, the prevalence rates of diastolic LV dysfunction and conduction disorders were mostly not clinically relevant and similar in AS patients and controls. In contrast, AS patients have an up to five times increased odds of AVR, although this was mostly mild. However, it is important to realize that any stage of AVR is considered to be pathological as mild regurgitation may progress and result into severe complications. When timely recognized, it can be treated adequately (aortic valve replacement). Therefore, our findings indicate that echocardiographic screening of elderly AS patients (50-75 years) should be considered. Obviously, prospective studies should assess the cost-effectiveness of screening of all AS patients as well as the long-term complications of AVR in AS patients.

Author Contributions: Conceptualization, S.C.H. and M.T.N.; methodology, M.B. and L.B.; validation, M.B., L.B. and S.C.H.; formal analysis, M.B. and L.B.; investigation, M.B., S.C.H. and L.B.; data curation, M.B., T.C.K. and L.B.; writing-original draft preparation, M.B.; writing-review and editing, L.B., S.C.H., V.P.v.H., M.L.H., T.C.K., I.E.v.d.H.-B., O.K. and M.T.N.; visualization, M.B. and L.B.; supervision, M.T.N.; project administration, M.B. and S.C.H.; funding acquisition, S.C.H. and M.T.N. All authors have read and agreed to the published version of the manuscript. 
Funding: This research was partially funded by ReumaNederland. The funder had no role in the study design, data collection, data analysis, manuscript preparation and publication decisions.

Institutional Review Board Statement: This study was approved by the Ethics committee of the Slotervaart Hospital/Reade (NL44202.048.13), and written informed consent was obtained from all patients prior to inclusion.

Informed Consent Statement: Informed consent was obtained from all subjects involved in the study.

Data Availability Statement: The datasets generated during and/or analyzed during the current study are available from the corresponding author upon reasonable request.

Acknowledgments: The authors are grateful to all study participants, as well as all rheumatology nurses involved in patients' management, and to Vidya Lall-Enait for the planning and management of all cardiac echoes at the Amsterdam UMC, location Vrije Universiteit Amsterdam.

Conflicts of Interest: The authors declare no conflict of interest.

\section{Appendix A}

Echocardiography Methods: Evaluation of LV function consisted of 2D, spectral and color flow Doppler recordings. 2D recordings were performed in parasternal long- and short-axis views, and apical four-, three- and two-chamber views. Aortic dimensions (cm), end diastolic volume (EDV, $\mathrm{mL}$ ) and end systolic volume (ESV, $\mathrm{mL}$ ) were obtained from the M-mode echocardiographic tracing. Left ventricular ejection fraction (LVEF), ESV and EDV were determined using the apical four- and two-chamber view using the modified biplane Simpson's method. Left atrial volume (LA volume) was determined using the apical four- and two-chamber view using the biplane Simpson's method or from 3D imaging. Left ventricular mass (LVM) was calculated with the following formula: 0.8 (1.04) ((end diastolic diameter $\left.(\mathrm{EDD})+\mathrm{IVS}+\mathrm{PWT})^{3}-\mathrm{EDD}^{3}\right)+0.6$ (in grams). Aortic and mitral valve function and tricuspid regurgitation velocity (TR velocity, $\mathrm{cm} / \mathrm{s}$ ) were evaluated using color Doppler flow. Pulsed-Doppler spectral recordings of the mitral inflow were obtained with the sample volume placed at the tips of the mitral leaflets. From the transmitral pulsed-Doppler recordings, peak E and A velocities $(\mathrm{cm} / \mathrm{s})$, the E/A ratio and the E wave deceleration times (DT, s) were obtained. Pulse wave tissue Doppler imaging was performed in the apical views to acquire mitral annular velocities. The sample volume was positioned at, or within, $1 \mathrm{~cm}$ of the septal ( $\left.\mathrm{e}^{\prime} \mathrm{sept}\right)$ and lateral ( $\mathrm{e}^{\prime}$ lat) insertion sites of the mitral leaflets. Average e' velocity is the average of e' septal and e' lateral velocity. Mitral $\mathrm{E} / \mathrm{e}^{\prime}$ was calculated by dividing mitral E velocity by mitral annular $\mathrm{e}^{\prime}$ velocity.

\section{References}

1. Braun, J.; Sieper, J. Ankylosing spondylitis. Lancet 2007, 369, 1379-1390. [CrossRef]

2. El-Maghraoui, A. Extra-articular manifestations of ankylosing spondylitis: Prevalence, characteristics and therapeutic implications. Eur. J. Intern. Med. 2011, 22, 554-560. [CrossRef]

3. Exarchou, S.; Lie, E.; Lindström, U.; Askling, J.; Forsblad-D’Elia, H.; Turesson, C.; Kristensen, L.E.; Jacobsson, L.T. Mortality in ankylosing spondylitis: Results from a nationwide population-based study. Ann. Rheum. Dis. 2016, 75, 1466-1472. [CrossRef] [PubMed]

4. Haroon, N.N.; Paterson, J.M.; Li, P.; Inman, R.D.; Haroon, N. Patients with Ankylosing Spondylitis Have Increased Cardiovascular and Cerebrovascular Mortality: A Population-Based Study. Ann. Intern. Med. 2015, 163, 409-416. [CrossRef]

5. Heeneman, S.; Daemen, M. Cardiovascular risks in spondyloarthritides. Curr. Opin. Rheumatol. 2007, 19, 358-362. [CrossRef]

6. Ozkan, Y. Cardiac Involvement in Ankylosing Spondylitis. J. Clin. Med. Res. 2016, 8, 427-430. [CrossRef]

7. Schilder, D.P.; Hufnagel, C.A.; Harvey, W.P. Rheumatoid Spondylitis and Aortic Insufficiency. N. Engl. J. Med. 1956, 255, 11-17. [CrossRef] [PubMed]

8. Brunner, F.; Kunz, A.; Weber, U.; Kissling, R. Ankylosing spondylitis and heart abnormalities: Do cardiac conduction disorders, valve regurgitation and diastolic dysfunction occur more often in male patients with diagnosed ankylosing spondylitis for over 15 years than in the normal population? Clin. Rheumatol. 2006, 25, 24-29. [CrossRef] [PubMed]

9. Klingberg, E.; Sveälv, B.G.; Täng, M.S.; Bech-Hanssen, O.; Forsblad-D’Elia, H.; Bergfeldt, L. Aortic Regurgitation Is Common in Ankylosing Spondylitis: Time for Routine Echocardiography Evaluation? Am. J. Med. 2015, 128, 1244-1250.e1. [CrossRef] [PubMed] 
10. Soroush, M.; Mominzadeh, M.; Ghelich, Y.; Soroosh, S.; Pasha, M. Investigation of Cardiac Complications and their Incidence in Patients with Ankylosing Spondylitis. Med. Arch. 2016, 70, 35-38. [CrossRef]

11. Bengtsson, K.; Forsblad-D’Elia, H.; Lie, E.; Klingberg, E.; Dehlin, M.; Exarchou, S.; Lindström, U.; Askling, J.; Jacobsson, L.T.H. Risk of cardiac rhythm disturbances and aortic regurgitation in different spondyloarthritis subtypes in comparison with general population: A register-based study from Sweden. Ann. Rheum. Dis. 2017, 77, 541-548. [CrossRef]

12. Forsblad-D'Elia, H.; Wallberg, H.; Klingberg, E.; Carlsten, H.; Bergfeldt, L. Cardiac conduction system abnormalities in ankylosing spondylitis: A cross-sectional study. BMC Musculoskelet. Disord. 2013, 14, 237. [CrossRef]

13. Longo, B.; Kirchner, L.A.; Simioni, J.; De Campos, A.P.B.; Skare, T.L. Electrocardiographic changes in spondyloarthritis and use of anti-TNF- $\alpha$ drugs: A retrospective study with 100 patients. Einstein 2019, 17, eAO4539. [CrossRef]

14. Heslinga, S.C.; Van Dongen, C.J.; Konings, T.C.; Peters, M.J.; Van der Horst-Bruinsma, I.E.; Smulders, Y.M.; Nurmohamed, M.T. Diastolic left ventricular dysfunction in ankylosing spondylitis-A systematic review and meta-analysis. Semin. Arthritis Rheum. 2014, 44, 14-19. [CrossRef] [PubMed]

15. Sveälv, B.G.; Täng, M.S.; Klingberg, E.; Forsblad-D’Elia, H.; Bergfeldt, L. Prevalence of diastolic dysfunction in patients with ankylosing spondylitis: A cross-sectional study. Scand. J. Rheumatol. 2015, 44, 111-117. [CrossRef] [PubMed]

16. Agca, R.; Heslinga, S.C.; Rollefstad, S.; Heslinga, M.; McInnes, I.B.; Peters, M.J. EULAR recommendations for cardiovascular disease risk management in patients with rheumatoid arthritis and other forms of inflammatory joint disorders: $2015 / 2016$ update. Ann. Rheum. Dis. 2017, 76, 17-28. [CrossRef] [PubMed]

17. van der Linden, S.; Valkenburg, H.A.; Cats, A. Evaluation of diagnostic criteria for ankylosing spondylitis. A proposal for modification of the New York criteria. Arthritis Rheum. 1984, 27, 361-368. [CrossRef]

18. Lang, R.M.; Badano, L.P.; Mor-Avi, V.; Afilalo, J.; Armstrong, A.; Ernande, L.; Flachskampf, F.A.; Foster, E.; Goldstein, S.A.; Kuznetsova, T.; et al. Recommendations for cardiac chamber quantification by echocardiography in adults: An update from the American society of echocardiography and the European association of cardiovascular imaging. Eur. Heart J. Cardiovasc. Imaging 2015, 16, 233-271. [CrossRef] [PubMed]

19. Lancellotti, P.; Tribouilloy, C.; Hagendorff, A.; Moura, L.; Popescu, B.A.; Agricola, E.; Monin, J.-L.; Pierard, L.A.; Badano, L.; Zamorano, J.L.; et al. European Association of Echocardiography recommendations for the assessment of valvular regurgitation. Part 1: Aortic and pulmonary regurgitation (native valve disease). Eur. J. Echocardiogr. 2010, 11, 223-244. [CrossRef]

20. Lancellotti, P.; Moura, L.; Pierard, L.A.; Agricola, E.; Popescu, B.A.; Tribouilloy, C.; Hagendorff, A.; Monin, J.-L.; Badano, L.; Zamorano, J.L.; et al. European Association of Echocardiography recommendations for the assessment of valvular regurgitation. Part 2: Mitral and tricuspid regurgitation (native valve disease). Eur. J. Echocardiogr. 2010, 11, 307-332. [CrossRef] [PubMed]

21. Du Bois, D.; Du Bois, E.F. A formula to estimate the approximate surface area if height and weight be known. 1916. Nutrition 1989, 5, 303-311, discussion 12-13. [PubMed]

22. Wang, H.; Bai, J.; He, B.; Hu, X.; Liu, D. Osteoarthritis and the risk of cardiovascular disease: A meta-analysis of observational studies. Sci. Rep. 2016, 6, 39672. [CrossRef]

23. Evangelista, A.; Flachskampf, F.A.; Erbel, R.; Antonini-Canterin, F.; Vlachopoulos, C.; Rocchi, G.; Sicari, R.; Nihoyannopoulos, P.; Zamorano, J.; Pepi, M.; et al. Echocardiography in aortic diseases: EAE recommendations for clinical practice. Eur. J. Echocardiogr. 2010, 11, 645-658. [CrossRef] [PubMed]

24. Bellamy, N.; Buchanan, W.W.; Goldsmith, C.H.; Campbell, J.; Stitt, L.W. Validation study of WOMAC: A health status instrument for measuring clinically important patient relevant outcomes to antirheumatic drug therapy in patients with osteoarthritis of the hip or knee. J. Rheumatol. 1988, 15, 1833-1840.

25. Nagueh, S.F.; Appleton, C.P.; Gillebert, T.; Marino, P.; Oh, J.K.; Smiseth, O.A.; Waggoner, A.D.; Flachskampf, F.A.; Pellikka, P.A.; Evangelisa, A. Recommendations for the Evaluation of Left Ventricular Diastolic Function by Echocardiography. Eur. J. Echocardiogr. 2008, 10, 165-193. [CrossRef] [PubMed]

26. Nagueh, S.F.; Smiseth, O.A.; Appleton, C.P.; Byrd, B.F., 3rd; Dokainish, H.; Edvardsen, T. Recommendations for the Evaluation of Left Ventricular Diastolic Function by Echocardiography: An Update from the American Society of Echocardiography and the European Association of Cardiovascular Imaging. Eur. Heart J. Cardiovasc. Imaging 2016, 17, 1321-1360. [CrossRef] [PubMed]

27. Paulus, W.J.; Tschope, C. A novel paradigm for heart failure with preserved ejection fraction: Comorbidities drive myocardial dysfunction and remodeling through coronary microvascular endothelial inflammation. J. Am. Coll. Cardiol. 2013, 62, 263-271. [CrossRef] [PubMed]

28. Paulus, W.J. Unfolding Discoveries in Heart Failure. N. Engl. J. Med. 2020, 382, 679-682. [CrossRef] [PubMed]

29. Okan, T.; Sari, I.; Akar, S.; Cece, H.; Goldeli, O.; Guneri, S.; Akkoc, N. Ventricular Diastolic Functions of Ankylosing Spondylitis Patients by Using Conventional Pulsed? Wave Doppler, Myocardial Performance Index, and Tissue Doppler Imaging. Echocardiography 2007, 25, 47-56. [CrossRef]

30. Acar, G.; Sayarlioglu, M.; Akcay, A.; Sokmen, A.; Sokmen, G.; Altun, B.; Nacar, A.B.; Gunduz, M.; Tuncer, C. Assessment of Atrial Electromechanical Coupling Characteristics in Patients with Ankylosing Spondylitis. Echocardiography 2009, 26, 549-557. [CrossRef]

31. Emren, S.V.; Gercik, O.; Ozdemir, E.; Solmaz, D.; Eren, N.; Simsek, E.C.; Tokac, M.; Emren, Z.; Kabadayi, G.; Akar, S. Evaluation of subclinical myocardial dysfunction using speckle tracking echocardiography in patients with radiographic and non-radiographic axial spondyloarthritis. Eur. J. Rheumatol. 2020, 7, 9-15. [CrossRef] 
32. Turkmen, S.; Askin, L.; Uzel, K.E.; Nacar, H.; Kavalci, V.; Akturk, E.; Selçuk, M.Y. Association of High-Sensitivity Troponin T With Left Ventricular Dysfunction in Ankylosing Spondylitis. JCR J. Clin. Rheumatol. 2020, 26, 87-93. [CrossRef] [PubMed]

33. Brewerton, D.; Goddard, D.; Moore, R.; Revell, P.; Gibson, D.; Jones, T.; Pease, C.; Shapiro, L.; Swettenham, K. The myocardium in ankylosing spondylitis: A Clinical, Echocardiographic, and Histopathological Study. Lancet 1987, 329, 995-998. [CrossRef]

34. Crowley, J.J.; Donnelly, S.M.; Tobin, M.; FitzGerald, O.; Bresnihan, B.; Maurer, B.J.; Quigley, P.J. Doppler echocardiographic evidence of left ventricular diastolic dysfunction in ankylosing spondylitis. Am. J. Cardiol. 1993, 71, 1337-1340. [CrossRef]

35. McMurray, J.J.; Adamopoulos, S.; Anker, S.D.; Auricchio, A.; Böhm, M.; Dickstein, K.; Falk, V.; Filippatos, G.; Fonseca, C.; Gomez-Sanchez, M.A.; et al. ESC Guidelines for the diagnosis and treatment of acute and chronic heart failure 2012: The Task Force for the Diagnosis and Treatment of Acute and Chronic Heart Failure 2012 of the European Society of Cardiology. Developed in collaboration with the Heart Failure Association (HFA) of the ESC. Eur. Heart J. 2012, 33, 1787-1847. [CrossRef]

36. Lang, R.M.; Badano, L.P.; Tsang, W.; Adams, D.H.; Agricola, E.; Buck, T.; Faletra, F.F.; Franke, A.; Hung, J.; De Isla, L.P.; et al. EAE/ASE recommendations for image acquisition and display using three-dimensional echocardiography. Eur. Heart J. Cardiovasc. Imaging 2012, 13, 1-46. [CrossRef] [PubMed]

37. Prasad, S.B.; Holland, D.J.; Atherton, J.J.; Whalley, G. New Diastology Guidelines: Evolution, Validation and Impact on Clinical Practice. Heart Lung Circ. 2019, 28, 1411-1420. [CrossRef]

38. Roldan, C.; Chavez, J.; Wiest, P.W.; Qualls, C.R.; Crawford, M.H. Aortic root disease and valve disease associated with ankylosing spondylitis. J. Am. Coll. Cardiol. 1998, 32, 1397-1404. [CrossRef]

39. Dik, V.; Peters, M.; Dijkmans, P.; Van Der Weijden, M.; De Vries, M.; Dijkmans, B.; Van Der Horst-Bruinsma, I.; Nurmohamed, M. The relationship between disease-related characteristics and conduction disturbances in ankylosing spondylitis. Scand. J. Rheumatol. 2010, 39, 38-41. [CrossRef]

40. Ward, M.M. Lifetime Risks of Valvular Heart Disease and Pacemaker Use in Patients with Ankylosing Spondylitis. J. Am. Heart Assoc. 2018, 7, e010016. [CrossRef] [PubMed]

41. Nishimura, R.A.; Otto, C.M.; Bonow, R.O.; Carabello, B.A.; Erwin, J.P., 3rd; Guyton, R.A. 2014 AHA/ACC Guideline for the Management of Patients with Valvular Heart Disease: A report of the American College of Cardiology/American Heart Association Task Force on Practice Guidelines. Circulation 2014, 129, e521-e643. [CrossRef] [PubMed]

42. Joint Task Force on the Management of Valvular Heart Disease of the European Society of Cardiology; European Association for Cardio-Thoracic Surgery; Vahanian, A.; Alfieri, O.; Andreotti, F.; Antunes, M.J. Guidelines on the management of valvular heart disease (version 2012). Eur. Heart J. 2012, 33, 2451-2496. [PubMed]

43. Ball, J. Enthesopathy of rheumatoid and ankylosing spondylitis. Ann. Rheum. Dis. 1971, 30, 213-223. [CrossRef] [PubMed]

44. Lubberts, E. The IL-23-IL-17 axis in inflammatory arthritis. Nat. Rev. Rheumatol. 2015, 11, 415-429. [CrossRef]

45. Sherlock, J.P.; Buckley, C.D.; Cua, D.J. The critical role of interleukin-23 in spondyloarthropathy. Mol. Immunol. 2014, 57, 38-43. [CrossRef] [PubMed]

46. Sherlock, J.P.; Joyce-Shaikh, B.; Turner, S.P.; Chao, C.C.; Sathe, M.; Grein, J. IL-23 induces spondyloarthropathy by acting on ROR-gammat+ CD3+CD4-CD8- entheseal resident T cells. Nat. Med. 2012, 18, 1069-1076. [CrossRef]

47. Bulkley, B.H.; Roberts, W.C. Ankylosing spondylitis and aortic regurgitation. Description of the characteristic cardiovascular lesion from study of eight necropsy patients. Circulation 1973, 48, 1014-1027. [CrossRef]

48. Davidson, P.; Baggenstoss, A.H.; Slocumb, C.H.; Daugherty, G.W. Cardiac and aortic lesions in rheumatoid spondylitis. Proc. Staff Meet. Mayo Clin. 1963, 38, 427-435. [PubMed]

49. Yildirir, A.; Aksoyek, S.; Calguneri, M.; Oto, A.; Kes, S. Echocardiographic Evidence of Cardiac Involvement in Ankylosing Spondylitis. Clin. Rheumatol. 2002, 21, 129-134. [CrossRef] 